\title{
Spiral Fracture of Long Bones in an Infant: Clinical and Biomechanical Challenges
}

\author{
Sheraz S Malik, Shahbaz S Malik, Mike D Jones and Peter S Theobald*
}

Institute of Medical Engineering and Medical Physics, Cardiff School of Engineering, Cardiff University, UK

The risk of a fracture from non-accidental injury is highest in the infant age group. The incidence of fractures in children increases with age [1], so infants have the lowest overall numbers of fractures. They are also most vulnerable to child abuse as they are entirely dependent on their carers, have a limited mobility and are completely defenceless. The incidence of a fracture from non-accidental injury in children under 18 months is estimated to be $4 / 10000 /$ year [2]. It is also estimated that in children under the age of 1 year, $25 \%$ to $50 \%$ of all fractures are due to non-accidental injury, with $40 \%$ to $80 \%$ of long bone fractures resulting from non-accidental injury [3]. Infants under 4 months with fracture are more likely to have been abused [4].

A spiral fracture of long bones of children was thought to be highly associated with non-accidental injury, but it is now recognised that it can equally occur from innocent injuries. However, literature is unclear about the significance of a spiral fracture of long bones of the very young infant. A common mechanism of an innocuous injury for this fracture is the child tripping over while running. However, an infant has very restricted mobility and this mechanism is unlikely to easily occur in the very young infant who is still non-ambulant. One study found spiral fracture pattern to be the most common abusive femoral fracture in children under 15 months [5] and no difference in the distribution of spiral fractures of femur from accidental and non-accidental injuries in children over 15 months [5] Similarly, a systematic review indicates that spiral fracture pattern is the most common type of humeral fracture from non-accidental injury in children less than 15 months However, this might be just because spiral and oblique fractures are more common in children under 15 months [6,7].

In the infant, clinical judgement on a non-accidental injury as the source of a spiral fracture of long bone is very difficult and clouded by the occurrence of stress fracture e.g. toddler's fracture in children, a broad spectrum of medical conditions that affect bone strength e.g. osteogenesis imperfecta, osteopenia of immaturity and rickets, and undiagnosed fractures from birth related trauma. The spiral fractures of femur are one of the common birth-related fractures, with an estimated incidence of 0.13 per 1000 live births [8]. These fractures are quite commonly unnoticed immediately post-partum as it difficult to associate features of pain with an underlying fractures in a newly born. A fracture is only suspected from unusual behavior, muscle tone, and lack of normal use of the limb. As a result, there is a delay in diagnosis of birth-related fractures in the majority of children. One study found a time delay of between 2-21 days in identifying post-partum femoral fractures [9]. This delay in diagnosis can lead to wrongfully suspecting child maltreatment [8].

A spiral fracture occurs whenatorsional (i.e. rotational) forceis applied to the bone. A torsional force acts to twist the bone about its longitudinal axis. The narrowest region of the bone is most susceptible to a spiral fracture, as it is the least stiff section of the bone and usually experiences the highest stresses. This is why spiral fractures in the tibia commonly occur in the narrow distal third [10]. In experimental studies the average angle of the spiral fracture to the longitudinal axis of the bone is found to be between $30^{\circ}$ and $40^{\circ}[11,12]$. This is in a good agreement with theoretically calculated angle of $45^{\circ}$, which is the plane of maximum tension under torsional force along which the fracture line propagates. However, in clinical experience, the spiral fracture angle can vary considerably from anywhere between $20^{\circ}$ to $90^{\circ}$ [13]. This difference between the experimental and clinical findings is due to bone anisotropy, moments caused by simultaneous contraction of muscles attached to the bone and bony appendages that distort fracture progression $[14,15]$. An in vivo torsional injury is also associated with a bending moment that prevents endless propagation spiral fracture line.

Biomechanical research utilising human tissues and animal models is continually improving our understanding of injury mechanism and thresholds for spiral fracture. However, our overall understanding of torsion strength properties of pediatric bones is much less than that of adults' bones. From a biomechanical point of view, a structure's strength under tensional load i.e. tensional strength is related to its material properties and its cross-sectional properties, but not to its length [16-18]. However, in children the cross-section of the bone is a function of its length; therefore as paediatric bones get longer, there is compensatory increase in cross-sectional diameter to maintain strength [19]. This has implications for animal bone models used to investigate characteristics of paediatric long bone fracture. The immature animal bone model must have suitable composition and dimensions to the equivalent long bones in a particular paediatric age group. Such a model could be used to estimate bone strength under a specific loading mode e.g. torsional loading. The restrictions in matching an animal bone model to paediatric bones means that transferable biomechanical data on threshold for fractures in children is scarce. Therefore, whilst there is a widely accepted requirement for objective, science-based injury assessment tools at presents the paucity of biomechanical data prevents correlation between the mechanics and a pediatric injury criterion. A greater understanding and acceptance of biomechanical models would improve clinical understanding of the underlying cause of fracture in a child.

\section{References}

1. Rennie L, Court-Brown CM, Mok JY, Beattie TF (2007) The epidemiology of fractures in children. Injury 38: 913-922.

2. Kemp AM, Dunstan F, Harrison S, Morris S, Mann M, et al. (2008) Patterns of skeletal fractures in child abuse: systematic review. BMJ 337: a1518.

3. Pierce MC, Bertocci GE, Vogeley E, Moreland MS (2004) Evaluating long bone

*Corresponding author: Peter S Theobald, Institute of Medical Engineering and Medical Physics, Cardiff School of Engineering, Cardiff University, Queens Buildings, The Parade, Newport Road, Cardiff, CF243AA, UK, E-mail: TheobaldPS@cardiff.ac.uk

Received May 23, 2013; Accepted May 25, 2013; Published May 27, 2013

Citation: Malik SS, Malik SS, Jones MD, Theobald PS (2013) Spiral Fracture of Long Bones in an Infant: Clinical and Biomechanical Challenges. J Trauma Treat 2: e113. doi:10.4172/2167-1222.1000e113

Copyright: (C) 2013 Malik SS, et al. This is an open-access article distributed unde the terms of the Creative Commons Attribution License, which permits unrestricted use, distribution, and reproduction in any medium, provided the original author and source are credited. 
Citation: Malik SS, Malik SS, Jones MD, Theobald PS (2013) Spiral Fracture of Long Bones in an Infant: Clinical and Biomechanical Challenges. J Trauma Treat 2: e113. doi:10.4172/2167-1222.1000e113

Page 2 of 2

fractures in children: a biomechanical approach with illustrative cases. Child Abuse Negl 28: 505-524.

4. Skellern CY, Wood DO, Murphy A, Crawford M (2000) Non-accidental fractures in infants: risk of further abuse. J Paediatr Child Health 36: 590-592.

5. Rex C, Kay PR (2000) Features of femoral fractures in nonaccidental injury. J Pediatr Orthop 20: 411-413.

6. Strait RT, Siegel RM, Shapiro RA (1995) Humeral fractures without obvious etiologies in children less than 3 years of age: when is it abuse? Pediatrics 96: 667-671.

7. Shaw BA, Murphy KM, Shaw A, Oppenheim WL, Myracle MR (1997) Humerus shaft fractures in young children: accident or abuse? J Pediatr Orthop 17: 293297.

8. Bilo RAC, Robben SGF, Van Rijn RR (2009) Forensic aspects of pediatric fractures: differentiating accidental trauma from child abuse. London: Springer, UK.

9. Morris S, Cassidy N, Stephens M, McCormack D, McManus F (2002) Birthassociated femoral fractures: incidence and outcome. J Pediatr Orthop 22: 27-30.

10. Tencer AF (2009) Biomechanics of fractures and fracture fixation. Rockwood and Green's fractures in adults, Volume 1. New York: Lippincott Williams \& Wilkins, USA.

11. Peterson DL, Skraba JS, Moran JM, Greenwald AS (1984) Fracture of long bones: rate effects under singular and combined loading states. J Orthop Res 1: 244-250.

12. Sammarco GJ, Burstein AH, Davis WL, Frankel VH (1971) The biomechanics of torsional fractures: the effect of loading on ultimate properties. J Biomech 4: 113-117.

13. Morgan EF, Bouxsein ML (2008) Biomechanics of bone and age-related fracture. Principles of bone biology (3rd edn) London Elsevier, UK.

14. Burstein AH, Frankel VH (1971) A standard test for laboratory animal bone. J Biomech 4: 155-158.

15. Ho KW, Gilbody J, Jameson T, Miles AW (2010) The effect of $4 \mathrm{~mm}$ bicortical drill hole defect on bone strength in a pig femur model. Arch Orthop Trauma Surg 130: 797-802.

16. Levenston ME, Beaupré GS, van der Meulen MC (1994) Improved method for analysis of whole bone torsion tests. J Bone Miner Res 9: 1459-1465.

17. Lind PM, Lind L, Larsson S, Orberg J (2001) Torsional testing and peripheral quantitative computed tomography in rat humerus. Bone 29: 265-270.

18. Jayaram MA ( 2007) Mechanics in materials with programs in C. Prentice-Hall New Delhi, India.

19. Petit MA, Beck TJ, Kontulainen SA (2005) Examining the developing bone: What do we measure and how do we do it? J Musculoskelet Neuronal Interact 5: 213-224. 